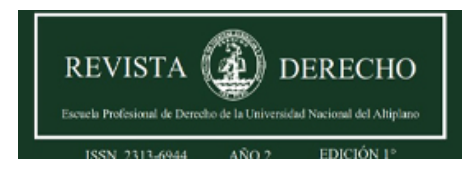

Revista de Derecho

ISSN: 2313-6944

ISSN: 2707-9651

revistaderecho@unap.edu.pe

Universidad Nacional del Altiplano

Perú

\title{
LA INVESTIGACIÓN PREPARATORIA EN LOS DELITOS DE CORRUPCIÓN DE FUNCIONARIOS EN EL NUEVO CODIGO PROCESAL PENAL
}

Dueñas Zuñiga, M.Dubcek

LA INVESTIGACIÓN PREPARATORIA EN LOS DELITOS DE CORRUPCIÓN DE FUNCIONARIOS EN EL NUEVO CODIGO PROCESAL PENAL

Revista de Derecho, vol. 5, núm. 2, 2020

Universidad Nacional del Altiplano, Perú

Disponible en: https://www.redalyc.org/articulo.oa?id=671870937003

DOI: https://doi.org/10.47712/rd.2020.v5i2.87

\section{(c) (7)}

Esta obra está bajo una Licencia Creative Commons Atribución 4.0 Internacional. 


\section{LA INVESTIGACIÓN PREPARATORIA EN LOS DELITOS DE CORRUPCIÓN DE FUNCIONARIOS EN EL NUEVO CODIGO PROCESAL PENAL}

The preparatory investigation in the crimes of corruption of officials in the new criminal procedure code

M.Dubcek Dueñas Zuñiga

Abogado Litigante de Defensa Privada., Perú
DOI: https://doi.org/10.47712/rd.2020.v5i2.87

Redalyc: https://www.redalyc.org/articulo.oa?

id $=671870937003$

Recepción: 30 Septiembre 2020

Aprobación: 25 Octubre 2020

Publicación: 27 Octubre 2020

\section{ReSUMEN:}

La forma de solucionar la impunidad de los delitos contra la Administración Pública como una meta del Derecho Penal en nuestra coyuntura nacional, estará siempre latente, para poder combatirse, la corrupción necesita ser mostrada. A través de la denuncia, los actos de corrupción salen a la luz pública para ser investigados y sancionados

En la presente investigación debemos tener como objetivo determinar la importancia que tiene la etapa de investigación preparatoria en los delitos de corrupción de funcionarios en el marco del Nuevo Modelo Procesal Penal y la relación que existe entre el inicio de la Investigación Preliminar y la formalización de la Investigación Preparatoria en el distrito judicial de Puno, para identificar de qué forma la disposición fiscal que declara la continuación y formalización de la investigación preparatoria contribuye al debido proceso con incidencia en el objeto y finalidad del proceso penal, para profundizar el análisis e interpretación realizados en la Investigación Preliminar.

Palabras ClaVE: Investigación Preliminar y Preparatoria, corrupción de funcionarios, sentencias condenatorias y absolutorias.

\section{ABstract:}

The way to solve impunity for crimes against Public Administration as a goal of Criminal Law in our national situation, will always be latent, to be able to fight, corruption needs to be shown. Through the complaint, the acts of corruption come to light to be investigated and punished

In the present investigation we must aim to determine the importance of the preparatory investigation stage in crimes of corruption of officials within the framework of the New Criminal Procedure Model and the relationship between the beginning of the Preliminary Investigation and the formalization of the Preparatory Investigation in the judicial district of Puno, to identify how the fiscal disposition that declares the continuation and formalization of the preparatory investigation contributes to due process with incidence on the object and purpose of the criminal process, to deepen the analysis and interpretation carried out in the Preliminary Investigation.

For the elaboration of the research work, the correlational and quantitative descriptive method was used, in turn applying the survey as an instrument; Taking as a hypothesis that the judges and trial lawyers surveyed perceive that the declaration of formalization of the preparatory investigation has significant importance and significance to move to the intermediate stage of the criminal process in the preparatory investigation courts of the judicial district of Puno.

KEYWORDS: Preliminary and Preparatory Investigation, corruption of officials, convictions and acquittals.

\section{PRESENTACIÓN}

El presente trabajo sustenta la problemática que cada día se hace más profunda en nuestro país, como es el de la corrupción de funcionarios, afecta a la confianza del ciudadano en el sistema o quebrar la conciencia de corresponsabilidad social y ello debe de llevar a la discusión sobre el modelo cultural que quiere adoptarse, y si en él se quiere o no integrar ese problema. Todo ciudadano peruano anhela largamente que las instituciones públicas del estado sean eficientes, eficaces y efectivas. 
La lucha contra la corrupción se libra, en buena medida, en el fortalecimiento de nuestras instituciones para combatir dichos delitos. Esta tarea debe considerarse una prioridad en la agenda pública.

El Ministerio Público forma parte de esta institucionalidad llamada a impulsar la reforma de la justicia en el Perú. Una reforma que, en el ámbito de la persecución penal, se traduce en la existencia de un aparato público eficiente y eficaz que asegure que la justicia alcance a todos y todas en pie de igualdad. Y a las dificultades que afronta el Ministerio Público para llevar a cabo su importante labor de perseguir la corrupción en el país. Lo hace, a propósito del estudio de denuncias archivadas por peculado y colusión en el marco del nuevo modelo procesal penal que rige en nuestro país, progresivamente, desde el año 2006.

Según la VIII Encuesta Nacional sobre Percepciones de la Corrupción en el Perú, el 86\% de la población percibe que los resultados de las denuncias por corrupción son poco o nada efectivas. ¿Por qué la ciudadanía percibe así? ¿Se trata de percepciones fundadas o infundadas? Lo ocurrido en Áncash y lo declarado por altas autoridades en los días posteriores a la detención de varias personas sindicadas como integrantes de una red de corrupción, sumado a la remoción e investigación por el Órgano de Control de varios fiscales de dicho distrito, pueden plantear serias dudas sobre si la cantidad y calidad de los archivos por casos de corrupción están bien fundamentados y sobre si estos son (o no) la manifestación de un fenómeno aislado y episódico.

\section{RESULTADOS Y DISCUSIÓN}

Es posible encontrar antecedentes históricos acerca de la etapa intermedia o de preparación de juicio, en la cual se ejercía el control sobre la acusación, en diversos sistemas de enjuiciamiento de la antigüedad. Así, en el procedimiento griego ante los heliastas, la acusación se presentaba ante el arconte, quien examinaba la acusación desde un punto de vista formal. En Roma, la accusatio estaba sujeta a control para luego elegirse un acusador para la formulación de la nominis delatio, en la cual se designaba al acusado y el hecho atribuido. (Vargas y Riego 2005). En Perú, desde el anteproyecto del CdePP de 1940 se planteaba la posibilidad de incluir una etapa intermedia en el proceso penal ordinario, en tanto se advertía la necesidad de una «cámara de acusación», cuerpo judicial intermedio entre la instrucción y el juez de fallo, que tenía como función especial fijar la procedencia o apertura de juicio oral, lo que haría un alto en el proceso, dando por concluida la instrucción y remitiéndola después de una breve apreciación a la jurisdicción que se estimara conveniente. Dicha pretensión no se logró materializar por los distintos problemas que generaba buscar un personal especializado para el control, nosotros consideramos, en el sentido que refiere San Martín Castro, que la etapa intermedia comienza con la emisión del auto judicial de elevación de la instrucción (artículo 203 del CdePP). Esta resolución, que se dicta cuando concluye el plazo de la investigación o cuando se han acumulado todas las actuaciones y diligencias en orden a la comprobación del delito y averiguación del presunto responsable, ocasiona la pérdida de competencia del juez penal y se la transfiere, para el desarrollo de diferentes actividades jurisdiccionales, a la Sala Penal Superior. Esta etapa culmina con la emisión del auto superior de enjuiciamiento (Villavicencio 2010).

Considero que el Fiscal pese a ser el director de la investigación no identifica adecuadamente los hechos del caso. En efecto, una correcta investigación fiscal debería partir no sólo de establecer claramente los hechos que podrían subsumirse en el delito investigado, sino además de determinar la atribución individual de los mismos, e incidir en las circunstancias precedentes, concomitantes y posteriores en cada caso; lo que en efecto no ocurre. Así también las deficiencias en la labor fiscal y judicial en las distintas etapas del proceso penal y que los actos de investigación efectuados por el fiscal en la etapa de investigación preparatoria son insuficientes para generar elementos de convicción que permitan sostener una acusación.

Las limitaciones del Fiscal como director de la investigación del delito en el Perú conforme a la praxis judicial son la falta de objetividad, los rezagos de un sistema inquisitivo, deficiencia en la formación profesional y el incumplimiento del principio de legalidad. A fin de poder resolver el problema planteado en la investigación se utilizó el método hermenéutico para el análisis de la doctrina y proceso penal con respecto 
a la función del Fiscal como director de la investigación a fin de contrastar su labor realizada en la práctica y lo que establece la doctrina. Para el análisis de la legislación del NCPP se empleó el método exegético que consistió en contrastar la labor fiscal realizada y lo que prescribe la legislación penal peruana.

\section{Etapa de Investigación Preparatoria}

El proceso común, establecido en el NCPP de 2004 se encuentra organizado de manera secuencial en las siguientes etapas: Investigación preparatoria (que incluye las diligencias preliminares), etapa intermedia y el juicio oral. En la etapa de la investigación preparatoria se encuentra destinada a verificar la concurrencia de las evidencias necesarias respecto de la ocurrencia de un hecho delictivo y de sus posibles autores o cómplices, a efectos de sostener una acusación o desestimar ella.

Por su parte la etapa intermedia, constituye una etapa "bisagra" que permite abrir o no la puerta del juicio oral; es una audiencia de preparación y saneamiento, en donde se discutirá si en efecto existe una "causa probable" que amerite ser sometida al debate probatorio del juicio oral. El Código a este respecto no ofrece una definición pero podría indicar que es una etapa de filtro que tiene como función, depurar errores y controlar los presupuestos o bases de la imputación y de la acusación, primero por el propio órgano acusador y luego por el órgano judicial, a fin de establecer si es viable para convocar debate penal pleno en el juicio oral, o si resulta el sobreseimiento o preclusión del proceso (Bovino 2005).

Por último, tenemos, el juicio oral, que constituye la etapa propiamente de juzgamiento, donde bajo los principios de inmediación, contradicción, concentración, oralidad y publicidad se actuarán todos los medios de prueba admitidos a las partes, para su respectivo debate en el plenario y posterior valoración por la judicatura, unipersonal o colegiada, de tal manera que las mismas funden la sentencia condenatoria o absolutoria (Villavicencio, 2010).

Uno de los grandes cambios que ha traído el NCPP es la etapa de investigación preparatoria, toda vez que, la etapa de investigación de estar en manos del Juez Instructor y pasara a constituirse en la función esencial del representante del Ministerio Público, quedando el Juez como un tercero imparcial que controlara los actos de investigación, de ahí que se le denomine, en otras latitudes, juez de garantías (Bramont, 1991).

Esta etapa de la investigación preparatoria, ha sido divida en dos fases, la fase de las diligencias preliminares y la fase de la investigación preparatoria propiamente dicha. En el que, las diligencias preliminares, a pesar de formar parte de la investigación preparatoria tiene un plazo de 60 días, luego de la modificatoria efectuada por la Ley Nro. 30076, sin perjuicio de que el fiscal pueda fijar un plazo distinto según las características, la complejidad y circunstancias de los hechos objeto de investigación. Mientras la fase de investigación propiamente dicha tiene un plazo de 120 días naturales, prorrogables por única vez hasta un próximo de 60 días simples. (Casación - La Libertad, 2008).

\section{Finalidad de la Investigación Preparatoria}

Según lo señalado por el artículo 321.1 del NCPP de 2004, la investigación preparatoria, persigue reunir los elementos de convicción, de cargo y de descargo, que permitan al Fiscal decidir si formula o no acusación y, en su caso, al imputado preparar su defensa. Tiene por finalidad determinar si la conducta incriminada es delictuosa, las circunstancias o móviles de la perpetración, la identidad del autor o partícipe y de la víctima, así como la existencia del daño causado.

La finalidad de la investigación preparatoria no es preparar solo la acusación sino que la actividad preliminar debe servir tanto para lo que determina la inculpación como para lo que la excluye, es decir, debe servir para preparar tanto la acusación como la defensa.

En resumen podemos señalar que la investigación preparatoria persigue dos finalidades principales: prepara el juicio oral y evitar juicios innecesarios, a través de una actividad investigativa, esto es, indagando para tratar de llegar al cabal conocimiento de los hechos y de las personas que en ellos participaron, consignando todas las circunstancias tanto adversas como favorables al autor o participe del delito (Cadavid y Bedoya, 2008).

\section{Dirección y Conducción de la Investigación Preparatoria}


En el código de procedimientos penales de 1940 la dirección de la investigación estaba a cargo del juez instructor, pero esto cambia radicalmente con la dación del NCPP, pues el director de la investigación es el Representante del Ministerio Público, teniendo el Juez la verdadera función que le corresponde, esto es, el ser un tercero entre las partes y controlar la constitucionalidad y legalidad de la actividad de investigación.

Ahora bien, en la etapa de investigación preparatoria el Fiscal cumple el rol activo en su calidad de titular de la acción penal, va a dirigir la investigación de los hechos que constituyen delitos actuando bajo los principios de legalidad y objetividad, por ello desde un inicio el efectivo Policial está obligado a comunicar la notitia criminis al representante del Ministerio Público, quien decidirá la estrategia a seguir en cada caso en especial, disponiendo la diligencias que considere necesarias" (Vargas, 2008).

Sin embargo, habrá ocasiones que por urgencia o peligro en la demora, será la Policía quien por iniciativa propia disponga la realización de determinadas diligencias, pero siempre tendrá que dar cuenta de ello al representante del Ministerio Público, su omisión o retraso, no generara la nulidad de la diligencia, sino solo la responsabilidad disciplinaria en el efectivo policial que incurrió en la irregularidad, por ello conforme lo establece el código de procedimientos penales la PNP, actúa y trabaja de la mano con el representante del Ministerio Público y ambos coordinan sus actuaciones y diligencias para un mejor y mayor esclarecimiento de los hechos materia de investigación.

\section{Principales Actuaciones en Delitos de Corrupción de Funcionarios.}

Conforme a la labor Fiscal las diligencias preliminares comprenden, principalmente, cuatro tipos de actuaciones: (i) toma de declaraciones, (ii) obtención de documentación de entidades, (iii) pericias y (iv) técnicas especiales de investigación (Ruesta y Sanchez, 2010).

En tal sentido, la diligencia más frecuente es la toma de declaraciones. No importa el distrito fiscal del que se trate, siempre es mayoritaria. Las declaraciones, por tanto, son la fuente más recurrida de acceso a información para dar forma a la teoría del caso, esta diligencia consideramos que es importante porque se obtiene de primera mano o fuente como se cometieron los hechos luctuosos en algunas ocasiones los investigados no declaran y mantienen silencio lo que obstruye y/o obstaculiza la investigación ya que es un derecho constitucional el no auto incriminarse o mantener silencio.

La segunda diligencia, en función a la frecuencia con que se practican, es el requerimiento de información que hacen los Fiscales de oficio. Lo que significa el acopio de información para tener mayores elementos de juicio Parte de la documentación es obtenida de los propios anexos, pero, en la mayoría de casos estudiados, los fiscales solicitan la remisión de información a la entidad vinculada a los funcionarios investigados. Mayormente solicitan informes en general y documentos variados, además de comprobantes de pagos y expedientes administrativos de la contratación o adquisición.

Por último, la utilización de técnicas especiales, tales como levantamiento de secreto de telecomunicaciones, bancario, tributario o bursátil, agente encubierto y vigilancia audiovisual electrónica es muy baja, hasta cierto punto es razonable que sea así. Estas técnicas suelen desplegarse luego de formalizada la denuncia, ya que uno de los objetivos de las diligencias preliminares es que sólo se realicen actuaciones urgentes e inaplazables, bajo la mira de determinar indicios razonables del hecho denunciado. Pero debe tenerse en cuenta también que la aplicación de las técnicas especiales de investigación tiene sus propias dificultades. Por ejemplo, el registro de llamadas, sólo es guardado por 3 años por las compañías telefónicas, con lo que en un tiempo relativamente corto se pierde la oportunidad de identificar los vínculos entre los investigados y terceros. Además, el principal problema con el levantamiento del secreto bancario es su demora, según los fiscales.

\section{Investigaciones Poco Profundas}

Muchas veces el representante del Ministerio Público Alude a investigaciones donde la documentación recabada proporcionaba evidencias del delito que hubieran podido ser identificadas con una investigación más acuciosa. No había más por recabar, simplemente era necesario ordenar la información en manos del fiscal y darle un sentido estratégico en apoyo de la teoría del caso que el Fiscal desarrollase. Es un problema 
íntimamente ligado a las técnicas de investigación para las cuales los fiscales cuentan con escasa orientación técnica y metodológica, esto se debe también a la poca preparación y falta de experiencia de los fiscales porque si tuvieran más práctica y experiencia, las investigaciones serían más prolijas y tendrían resultados positivos que eso debería ser el norte o lo usual, lo que no ocurre muchas veces conforme se verifica en la práctica.

Estos casos evidencian, sino una falta de capacidad, sí al menos una de planificación de la investigación. Los defectos que se aprecian en la disposición de archivo no son más que la consecuencia de cómo se planificó y llevó a cabo la investigación. De ahí que, en las disposiciones Fiscales, haya una debilidad manifiesta en el análisis de las evidencias, la claridad de las causas del archivo, así como en la determinación de la valoración de cada medio probatorio.

\section{No planificación de Diligencias Importantes}

También se han visto casos que se archivan por la no realización de diligencias importantes. En algunos casos, se advirtió el fuerte vacío de posibles evidencias que no fueron tomadas en cuenta en la investigación y que habrían determinado la conclusión de los mismos.

Por ello muchas veces los archivos del fiscal terminan estando poco fundamentadas y amparadas en muy poca información relevante. El Fiscal, al señalar que la sola sindicación del denunciante no era suficiente y de que no existía medio probatorio alguno, termina en la práctica transfiriéndole al denunciante la carga de la prueba, para esclarecer los hechos. Es claro que el Fiscal debe verificar el contenido de la denuncia y recoger los indicios probatorios necesarios no sólo a través de las citaciones, sino además solicitando información a las partes que intervienen en la investigación.

\section{Juicio Oral}

El juicio oral es aquel período o fase que se desarrolla en todos los procedimientos penales en el que, una vez concluida la instrucción o investigación y la fase de acusación provisional, se practican las pruebas y efectúan las alegaciones en presencia del juez o tribunal competente para dictar la sentencia.

En esta etapa:

1. El Juez de Juicio Oral escuchará a la Defensa y al Ministerio Público,

2. Se actúan las pruebas,

3. Se emiten los alegatos de clausura o finales por las partes,

4. Finalmente se delibera, se emite el fallo y se dicta una sentencia en la que se explica oralmente si el Imputado es inocente o culpable.

Por ello sostenemos que la investigación preparatoria en los delitos de corrupción de funcionarios no se realizan conforme a ley. Y tienen serias deficiencias y muchas veces algunos representantes del Ministerio Público reproducen las diligencias que se realizaron en la investigación preliminar en la investigación preparatoria lo que de por si deviene en improductiva y a causa de ello muchas investigaciones se archivan lamentablemente hemos conocido de requerimientos donde simplemente se describen los presupuestos fácticos y la calificación jurídica, sin que se realice el proceso de subsunción del hecho delictuoso a la conducta típica. Muchas veces solamente se enumeran los elementos de convicción sin ofrecer el detalle, uno por uno, de por qué el fiscal los considera «evidentes». Y este trabajo le corresponde al Fiscal, porque es su caso: el Juez no puede subrogarlo ni adivinar o interpretar su razonamiento sin una base. En estos supuestos, el Juez puede solicitarle al Fiscal que subsane las omisiones al otorgarle un plazo para luego pronunciarse sobre el fondo o, en su defecto, declarar la improcedencia por falta de motivación, que también permite la presentación del mismo requerimiento, aunque bien hecho. Sostenemos que el control que realiza el juez se adecua al que desarrolla en la audiencia de control de la acusación, pero tomando en cuenta las observaciones que realicen los demás sujetos procesales que tienen derecho a opinar sobre su procedencia o no procedencia. Se advierte que, en este proceso especial, la norma no establece que el juez le fije un plazo al fiscal para que formule la acusación bajo responsabilidad disciplinaria.

Considero que, una vez que el Juez recibe el requerimiento de acusación, debe ponerlo en conocimiento de los demás sujetos procesales para evitar acusaciones sorpresivas que están proscritas. La norma establece 
simplemente que la acusación será remitida por el Juez de la investigación preparatoria al Juez penal competente para que dicte acumulativamente el auto de enjuiciamiento y de citación a juicio.

\section{CONCLUSIONES}

El nuevo modelo procesal penal, es virtuoso y formal y otorga todas las garantías de ley a las partes procesales y muchas veces los fiscales no cumplen dicha función por falta de experiencia y conocimiento, lo que finalmente conlleva a que muchos delitos de corrupción de funcionarios queden impunes y no se sancionen conforme a ley, lo que denota un mal precedente para la administración de justicia, por ello considero que la etapa más importante de la investigación fiscal es la etapa de investigación preparatoria y al no realizarse conforme a ley. Porque muchas veces los fiscales repiten las mismas diligencias que se realizan en la etapa de investigación preliminar. Lo que trae como consecuencia el archivamiento de las investigaciones, debido a ello los fiscales que están cargo de investigaciones de delitos de corrupción de funcionarios deben estar mejor preparados y tener presente el código de ética de su institución para que realicen su labor de manera prolija y eficiente en beneficio del estado.

\section{BIBLIOGRAFÍA}

BOVINO, Alberto (2005). Principios políticos del procedimiento penal. Buenos Aires: Editores del Puerto S.R.L.

BRAMONT-ARIAS, Luis. (1991) Manual de Derecho Penal (Parte Especial.). Lima, San Marcos, 4 ed., 1991.

CADAVID BOTERO, Mario Nicolás y BEDOYA SIERRA, Luis Fernando (2008). La fase de investigación y la fiscalía en el sistema acusatorio colombiano. En: Reflexiones sobre el sistema acusatorio -Una visión desde la práctica judicial-, varios autores. Librería Jurídica Sánchez R. Ltda., Medellín (Colombia).

CASACIÓN 02-2008. La Libertad.

RUESTA, Róger Yon; SÁNCHEZ MÁlAGA, Armando (2010). Aportes de orden pragmático ante la implementación del nuevo Código Procesal Penal Derecho.PUCP, núm. 65, pp. 159-175.

VARGAS, Juan Enrique y RIEGO Cristian (2005). Reformas procesales penales en América Latina, Resultados del Proyecto de Seguimiento. Centro de Estudios de la Justicia de las Américas, Santiago, p. 215.

VARGAS VIANCOS, Juan Enrique (2008). La Nueva Generación de Reformas Procesales Penales en Latinoamérica. URVIO, Revista Latinoamericana de Estudios de Seguridad, núm. 3, pp. 33- 47.

VILLAVICENCIO RÍOS, Frezia (2010).Apuntes sobre la celeridad procesal en el nuevo modelo procesal penal peruano. Derecho PUCP, núm. 65, pp. 93-114. 